\title{
Hypoplastic coronary artery disease: report of one case
}

\author{
N Amabile, A Fraisse, J Quilici
}

Heart 2005;91:e12 (http://www.heartjnl.com/cgi/content/full/91/2/e12). doi: 10.1136/hrt.2004.047621

Hypoplastic coronary artery disease (HCAD) is a rare abnormality with a high rate of sudden death and poor outcome. HCAD was revealed by myocardial infarction in a teenager with objective evidence of silent ischaemia on myocardial scintigraphy. After four years of follow up, he suddenly collapsed during exercise and subsequently died. Although HCAD is very uncommon, it should be actively excluded in children and young adults who experience sudden cardiac death. Aggressive treatment such as implantable cardioverter-defibrillator or heart transplantation may be indicated for this rare coronary abnormality.

$\mathrm{H}$ ypoplastic coronary artery disease (HCAD) is a rare congenital abnormality with a high rate of sudden death and poor outcome. ${ }^{1-7}$ We previously published the initial presentation of a child with HCAD revealed by acute myocardial infarction. ${ }^{1}$ We report here his subsequent evolution and outcome in, to our knowledge, the first documented and longest follow up of this syndrome.

\section{CASE REPORT}

An 11 year old boy with a history of asthma was admitted to the paediatric intensive care unit for a non- $\mathrm{Q}$ wave anterior myocardial infarction. During sustained exercise (a handball match), he suddenly collapsed and recovered after a brief cardiopulmonary resuscitation. He presented with chest pain, anterior ST segment depression on the ECG, and increased creatine kinase concentration (peak $2580 \mathrm{U} / \mathrm{l}$; MB fraction $240 \mathrm{U} / \mathrm{l})$. During the acute phase, he received anticoagulation medications, aspirin, and calcium inhibitors. Cardiac catheterisation was performed eight days after an uncomplicated intensive care unit course. Left ventriculography showed apical hypokinesia with a mildly depressed ejection fraction (55\%). Selective coronarography showed hypoplasia of the distal left anterior descending coronary artery (LAD) and right coronary artery (RCA) with no supply to the inferior aspect of the interventricular septum by a posterior branch of the RCA or left circumflex coronary artery. Additionally, no diagonal branches arising from the LAD but well developed collateral branches issuing from septal perforating arteries were documented. Intracoronary infusion of glyceryl trinitrate did not change the diameter or the morphology of the coronary arteries. Total cholesterol and high density lipoprotein (HDL) cholesterol, sedimentation rate, serological studies for connective tissue diseases, antithrombin III, proteins $\mathrm{C}$ and $\mathrm{S}$, endogenous tissue plasminogen activator, and plasminogen activator inhibitor were normal. The final diagnosis was HCAD. The patient was discharged and prescribed diltiazem after a normal maximal exercise test 16 days after his admission. He was told to avoid any kind of sustained exercise.

One year after the initial presentation, the patient remained asymptomatic. Physical examination and ECG were normal. The echocardiogram showed an apical hypokinesia with normal ejection fraction and 24 hour Holter monitoring did not show silent ischaemia or arrhythmia. A stress test with thallium-201 imaging was performed and showed a perfusion defect involving the anteroseptal and apical segments with incomplete apical redistribution at rest (fig 1). A new cardiac catheterisation showed an apical dyskinesia on the ventriculogram and hypoplasia of the RCA and distal LAD with no diagonal branches (fig 2). A myocardial bridge, not recognised on the previous cardiac catheterisation, was documented at the distal LAD site. Close follow up with maintenance of calcium inhibitor and avoidance of any kind of physical exercise was the agreed course of action. A new stress test with thallium 201 imaging performed one year later showed persistence of the defects and ischaemia previously documented. The patient remained asymptomatic and physical examination, ECG, and 24 hour Holter monitoring were normal during the follow up. The left ventricular function on the echocardiogram did not worsen during follow up.

One year later, the diltiazem was interrupted because the patient had symptomatic orthostatic hypotension. Despite
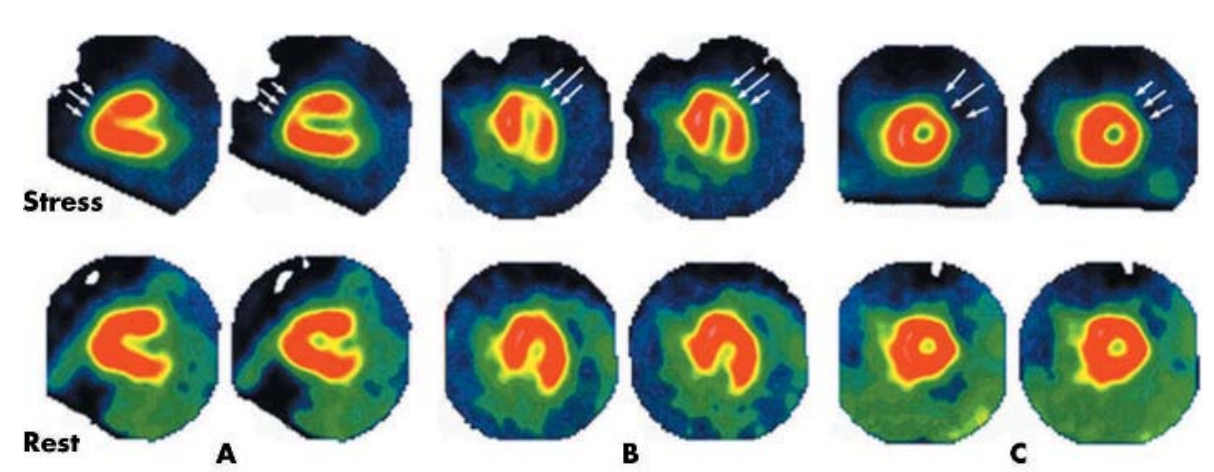

Figure 1 Thallium-201 perfusion scintigraphy showing an apical and anteroseptal defect during stress with incomplete redistribution at rest (arrows). (A) Sagittal views. (B) Transverse views. (C) Frontal views.

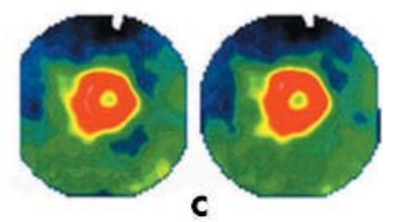



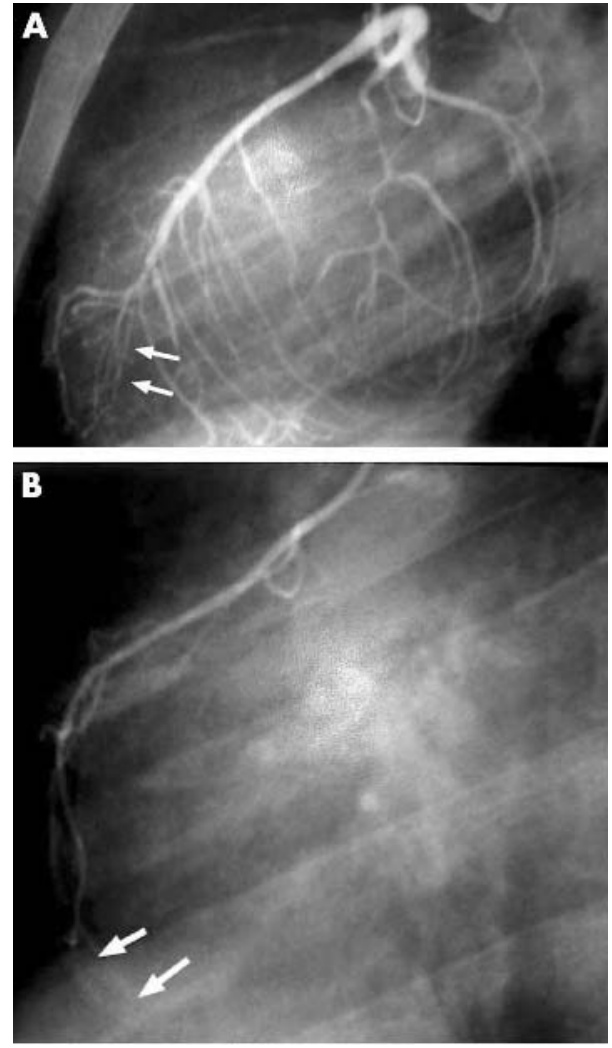

Figure 2 (A) Left anterior oblique left main coronary artery angiogram showing a hypoplastic distal left anterior descending coronary artery (arrows). Septal branches are well developed and supply the basal part of the interventricular septum. In contrast, no diagonal branches are seen on the anterolateral free wall of the ventricle and no posterior branch issuing from the left circumflex artery. (B) Lateral view angiogram showing hypoplastic right coronary artery without posterior descending artery and no supply to the basal part of interventricular septum (arrows).

the recommendation to avoid exercise, the patient decided to play a handball match a few days later. He suddenly collapsed during the match, after he finished a run. Cardiac monitoring during the unsuccessful cardiopulmonary resuscitation showed ventricular fibrillation. He died on June 2001 at age 15, four years after his initial presentation.

\section{DISCUSSION}

HCAD was first reported in $1970^{2}$ and refers to congenital underdevelopment of one or more major branches of the coronary arteries with greatly decreased luminal diameter or length. ${ }^{3}$ The majority of the reported cases are isolated and often diagnosed at necropsy..$^{2-4}$ Ogden et $a l^{3}$ found an incidence of $0.022 \%$ of hypoplastic proximal coronary artery in a study of 224 necropsy cases of congenital artery anomalies. ${ }^{2}$ In living patients the diagnosis is made by coronary angiography. ${ }^{156}$ In a recent analysis of 58023 coronary angiographies performed in adult patients, coronary artery anomalies were diagnosed in 257 patients $(0.44 \%)$ with congenital atresia in only 16 patients (atretic RCA in two patients; atretic left circumflex in 14). ${ }^{5}$ However, the true incidence of HCAD in the general population (children and adults) is unknown.

HCAD is often revealed by sudden death, especially in young adults and athletes. ${ }^{34}$ Myocardial infarction is an unusual presentation pattern, although in our patient HCAD was found because of a probably life threatening arrhythmia, since the patient collapsed at initial presentation.
All authors, despite several reports, do not admit a correlation between HCAD and ischaemia. ${ }^{167}$ In our patient, detailed follow up is available with nuclear cardiological documented evidence of persistent myocardial ischaemia despite no clinical symptoms (fig 1). The apical and anteroseptal defects during stress with incomplete redistribution at rest on thallium scintigraphy result from silent ischaemia or the presence of hibernating myocardium. In healthy people, collateral branches issuing from the RCA or the distal LAD supply this myocardial area. In our patient, as the RCA and distal LAD were underdeveloped, collateral vessel flow to the left ventricle was insufficient, leading to inadequate stress perfusion.

Circumstances surrounding the death of our patient are comparable with previously reported deaths caused by HCAD (ventricular arrhythmia during effort), consistent with a sudden and total occlusion of the LAD. ${ }^{3}$ The mechanisms involved may be a coronary artery spasm reflecting abnormal vasodilator mechanisms and endothelial dysfunction ${ }^{7}$ or intramural thrombus as reported for four of seven patients in the study of Zugibe et $\mathrm{al}^{4}$. An additional deleterious role of the myocardial bridge is possible in our patient.

In selected patients with proximal HCAD and a well developed distal network, surgical treatment with coronary artery bypass can be proposed. ${ }^{6}$ Heart transplantation may also be considered for patients who develop ischaemic cardiomyopathy with end stage heart failure. In our patient, coronary artery bypass was not indicated because of the diffuse and distal coronary hypoplasia. Since he never experienced clinical heart failure and his left ventricular function was normal on the follow up echocardiograms, heart transplantation was not considered. However, although the ECG and 24 hour Holter monitoring were normal during follow up, an implantable cardioverterdefibrillator could have been proposed, since there was persistent myocardial ischaemia on the scintigraphy and sudden death is a frequent issue in this coronary abnormality. ${ }^{4}$ Unfortunately in our centre, implantable cardioverterdefibrillators were not routinely used in the paediatric population at the time of the patient's presentation and follow up.

In conclusion, HCAD is an uncommon abnormality rarely diagnosed in living patients. It should be actively excluded in children and young adults who experience sudden cardiac death. The prognosis is poor and treatment options are limited. In patients with evidence of myocardial ischaemia, the implantation of a cardioverter-defibrillator should be strongly considered.

\section{Authors' affiliations}

N Amabile, A Fraisse, J Quilici, Département de cardiologie, Hôpital de la Timone, Marseille, France

There is no potential or real conflict of interest with this manuscript.

Correspondence to: Dr Alain Fraisse, Département de cardiologie, Hôpital de la Timone, 264 rue St Pierre, 13385 Marseille Cedex 05, France; alain.fraisse@ap-hm.fr

\section{August 2004}

\section{REFERENCES}

1 Fraisse A, Quilici J, Canavy I, et al. Myocardial infarction in children with hypoplastic coronary arteries. Circulation 2000;101:1219-22.

2 Ogden JA. Congenital anomalies of the coronary arteries. Am J Cardiol 1970;25:474-9.

3 Roberts WC, Glick BN. Congenital hypoplasia of both right and left circumflex coronary arteries. Am J Cardiol 1992;70:121-3.

4 Zugibe FT, Zugibe FT Jr, Costello JT, et al. Hypoplastic coronary artery disease in the spectrum of sudden unexpected death in young and middle age adults. Am J Forensic Med Pathol 1993;14:276-83. 
5 Göl MK, Özatik MA, Kunt A, et al. Coronary anomalies in adult patients. Med Sci Monit 2002;8:CR636-41.

6 Casta A. Hypoplasia of the left coronary artery complicated by reversible ischemia in a newborn. Am Heart J 1987;114:

1238-41.
7 Angelini P Velasco JA Flamm S Coronary anomalies: incidence, pathophysiology and clinical relevance. Circulation 2002;105:2449-54. 8 Gradaus R, Wollman C, Köbe J, et al. Potential benefit from implantable cardioverter-defibrillator therapy in children and young adolescents. Heart 2004;90:328-9. 